\title{
ETHICS AND NEPALESE DOCTORS
}

The society expects that a doctor serves the suffering people and in doing so puts the patients' interests above his own. A person who takes a physician's vocation may do so for a number of reasons: s/ he may have found a physician's status in the society attractive, s/he might have been attracted by the possibility of making money or s/he may be genuinely interested in relieving the pain and disease of the suffering masses. Whatever may be the motive of joining the profession, a physician is seen in an advantageous position in relation to a person who is sick. There is a possibility that a physician may try to exploit the relationship to his or her advantage, because the patient is not in a position to bargain or argue lest he/ she may forfeit the opportunity to get relieved of the problems. In order to avoid such a situation, society in general tries to establish definite legal provisions to regulate the medical practice. Similarly, the professional bodies like medical councils have also developed certain code of ethics. These are external rules, which govern a person in his/ her daily work with the patients; however, there may be certain values inherent in the physicians, which also guide or motivate them to act in a certain way.

What one learns in the medical school and from one's teachers will determine how one will act professionally. Similarly the family background, the societal values and the practices of the peers also determine how a physician practices medicine.

With the improvement in communication network and easy transmission of new ideas, the world is becoming a global village. Thus the possibility of one getting influenced by the ideas in far away places also influence the way medicine is practiced. These internal and external factors are likely to influence medical profession in Nepal as well.

Some form of code of conduct for the physicians has existed in our society since antiquity. The most often quoted reference is made to one mentioned in Charak Samhita. Physicians trained in modern system of medicine have bee introduced to and usually swear by Hippocratic oath. ${ }^{1}$

In the current times, physicians in Nepal have tried to develop mechanisms to enable them to practice medicine in an ethical way. In order to keep its members within the ethical path, Nepal Medical Council has developed a code of ethics ${ }^{2}$ for its members. The NMC code of ethics is based on international conventions on the subject and has laid down guidelines on how to conduct oneself in dealing with patients, with colleagues, in setting practice, advertisement of services, charging fees etc. NMC has a standing ethics committee that considers the complaints against its member.

Nepal Health Research Council (NHRC), another national institution that supervises the research activities in the country, has laid down the guidelines, which are followed while reviewing the research proposal. ${ }^{3}$ Physicians conducting research have to follow those guidelines.

Are those guidelines and codes adequate to help 
the physicians to practice medicine ethically? There are a number of situations in which the guidelines are quite inadequate to resolve the ethical dilemma a physician may face.

Some of the situations where there may not be any clear answer are as follows:

a. Who is responsible for deciding the course of treatment in a patient: patient him/herself or their relatives or the doctor? How much a doctor can take upon himself/ herself to decide regarding the plan of investigations or treatment? To what extent a busy doctor can involve the patient in deciding the treatment? When does a doctor have to take consent from the patient or patients' party? What should be the process of taking consent?

b. Doctors have been taught to treat a certain ailment in a certain way but the situation of the patient or the health delivery system is such that the doctor can not practice what is best for the patients. What does one do in such a situation? Should we always consider the patients' context and accept "sub-standard" or "unscientific treatment" as the right one?

c. The legal provisions which look anachronistic and not in consonance with the prevalent human rights and values: the question of abortion as an individual's right is not accepted by the law in Nepal but the modern feminists' views are to the contrary. It is a difficult question to resolve whether a doctor is allowed to have his/her personal opinion on this or not and whether a doctor is allowed to practice according to one's own conscience.

d. Introduction of newer effective but very expensive technology that may benefit a few wealthy in a community where basic health facilities are lacking also creates dilemma. For example: expensive cardiac transplantation services in a country where there is no program for the prevention of rheumatic fever, in-vitro fertili- zation in a country with population problem.

e. Whether women should be provided services for sex determination that may lead to aborting of a fetus of unwanted sex? Should we comply with the parent's wish or look after the unborn child's interest?

f. Who is the right person to decide about the type of treatment to be carried out in case of an adult patient? Is it the patient or his/her family members? Should a patient be told about a life threatening or incurable disease disregarding the psychological trauma it can cause to the patient? What should one do if the diagnosis is such that it would reflect poorly on patients past life and cause conflict in the family? What should one do if the disclosure of the diagnosis can cause serious harm to the patient?

g. The paucity of resources can create a situation of ethical dilemma for the doctor. What should one do when there is more than one claimant to a service, which can be provided to only person at a time? Who should get the priority? Can age, sex, social status, type of the disease etc decide who should get the treatment? Or it should be open and on the first come first served basis.

h. Should one consider the issue of equitable distribution of the health services while deciding to start a secondary or tertiary care health facility? Should one consider the impact of a big health facility on the existing health care system in the area or not?

i. What ethical considerations should guide our research agenda? How far can one consider the aspects of autonomy and informed consent in a community or society with limited education? Can we accept standards different from those of the developed countries while enrolling subjects into study? What level of compensation or support is acceptable for our country?

j. Is it likely that topics like "assisted death", euthanasia, organ transplantation and cloning 
will become issues of ethical concern for us in near future? If it is likely, what should be our state of preparedness?

$\mathrm{k}$. What are the responsibilities of the patients? How can one differentiate between a genuine search for a second opinion from a restless "medical shopping" without the knowledge of primary physician?

The present code of ethics does not have any answers to these questions. Medical councils in the developed countries ${ }^{4,5}$ have revised their code of ethics and tried to incorporate simple guidelines to resolve the likely dilemma that can arise in day- today practice. The modern approach is to base the code on the fundamental ethical principles of medicine, especially doing good (beneficence), doing no harm (nonmaleficence), respect for the persons (autonomy), justice and compassion. Additionally, the development in human rights and current bioethical discussion also need to be considered.

In view of these changes, the present NMC Code of Ethics needs revision. The revised version should include the issues of informed consent (to ensure autonomy), responsibilities to society (to promote justice and prevent nonmaleficence) and guidelines on clinical research. A wider discussion with jurists, human right activists, consumers of health services, researchers and bio-ethicists should precede the drafting of the revised code of ethics.

However, the development of a modern code of ethics is only a part of the game.

A code of ethics provides the content, which a doctor should be familiar with but it does not prepare him or her to apply them in their daily practice. Doctors need training in the application of this body of knowledge and that requires appropriate training. The current situation regarding the education in medical ethics is unlikely to prepare the future doctors to deal with the ethical dilemmas they may face. Similarly, we do not have mechanism to provide continuing education to the doctors to identify and face the ethical dilemmas. Majority of us are doing what we think is right best to our knowledge and common practices. Many of our actions could be considered unethical if seen from the perspective of a modern bio-ethicists, some of the actions may be outright illegal according to the law of the land but scientifically correct or appropriate according to one's moral values.

It is important that discussion on the concept of ethics and the sources of ethical dilemma is kept in the agenda for discussion in different forum of health professionals. This commentary is an attempt to bring this issue to the attention of all concerned.

\section{Dr. Ramesh K. Adhikari, MD}

Professor of Child Helath

Campus Chief, Maharajgunj Campus

T.U., Institute of Medicine.

\section{REFERENCES:}

1. Jayweera BA: Ethical issues in health, Discussion paper presented at SEA Advisory Committee on Health Research, Dharan, Nepal, April'96

2. Nepal Medical Council: NMC Code of ethics, NMC, Kathmandu, Nepal.

3. NHRC: NHRC Guidelines for ethical review (draft): Kathmandu, Nov.2000

4. Code of ethics of Canadian Medical Association (Approved by general council, 1996, Canada)

5. British Medical Association: Draft revision of Hippocratic Oath, 1998. London 1997.

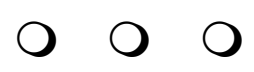

